Louisiana State University LSU Digital Commons

2001

\title{
Developing consensus indicators of sustainability for southeastern United States aquaculture
}

Rex H. Caffey

Follow this and additional works at: http://digitalcommons.lsu.edu/agexp

\section{Recommended Citation}

Caffey, Rex H., "Developing consensus indicators of sustainability for southeastern United States aquaculture" (2001). LSU Agricultural Experiment Station Reports. 650.

http://digitalcommons.1su.edu/agexp/650 


\section{Developing Consensus Indicators of Sustainability for Southeastern United States Aquaculture}

\section{Rex H. Caffey,}

Richard F. Kazmierczak, Jr., and James W. Avault, Jr.

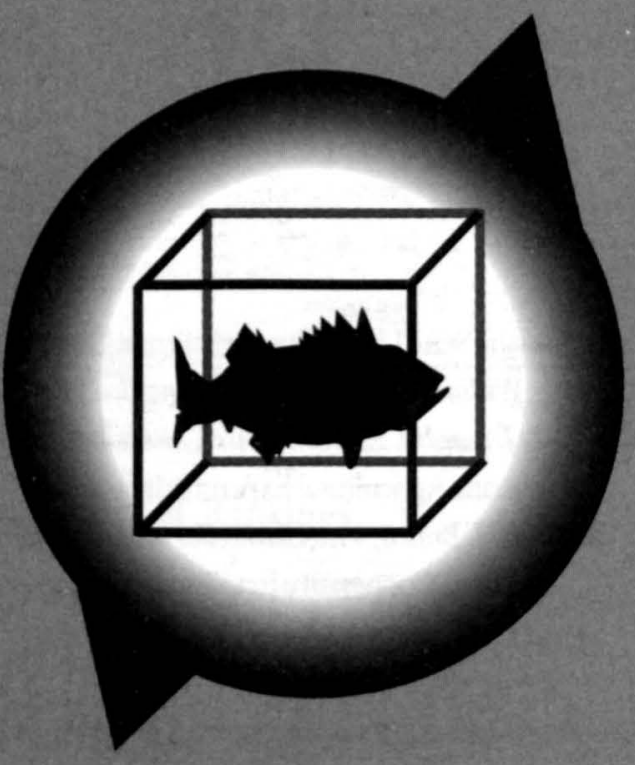




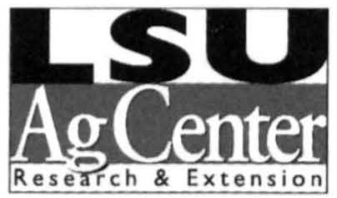

\section{Visit our Web site: www.lsuagcenter.com}

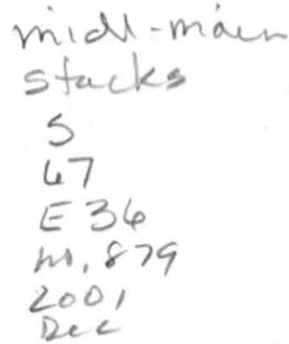

Louisiana State University Agricultural Center

William B. Richardson, Chancellor

L. J. Guedry, Executive Vice Chancellor

Louisiana Agricultural Experiment Station

William H. Brown, Vice Chancellor and Director

Louisiana Cooperative Extension Service

Paul D. Coreil, Vice Chancellor and Director

The LSU AgCenter provides equal opportunities in programs and employment. 


\section{Table of Contents}

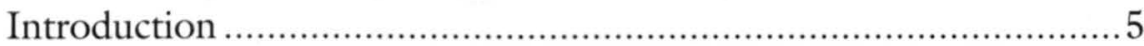

Sustainability and Aquaculture ............................................... 7

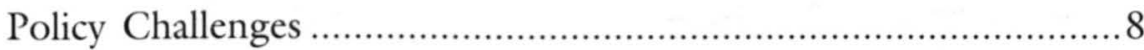

Data and Methods ................................................................... 11

Survey Specifics ...................................................... 12

Nonparametric Methods ........................................... 14

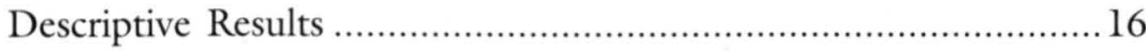

Disciplinary Weights ................................................. 19

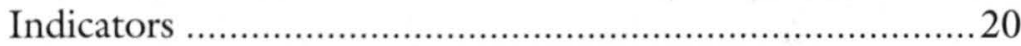

Description of Indicators ...............................................23

Indicator Weightings .............................................. 24

Ordinal Ranking Analysis ...........................................................26

Freidman's Test of Rankings .......................................26

Kendall's Test for Convergence ....................................... 30

Consensus Rankings ...................................................... 33

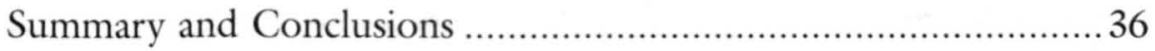

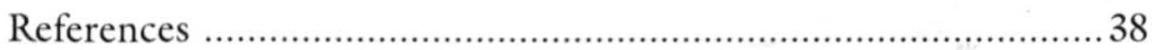

\section{LSULIBRARY $=B A$}




\title{
Developing Consensus Indicators of Sustainability for Southeastern United States Aquaculture
}

\author{
Rex H. Caffey, \\ Richard F. Kazmierczak, Jr., \\ and James W. Avault, Jr.
}

\section{Introduction}

The term sustainability originally referred to agricultural and industrial technologies that reduced or prevented the environmental degradation often associated with economic activity. Today, sustainability is associated with a holistic consideration of the economic, environmental and sociological impacts of any development. The United States aquaculture industry has been promoting the idea of sustainability (Hopkins 1996), with cooperation among producers, researchers and regulatory agencies considered vital to the development of sustainable aquaculture policy (Sandifer 1995; NADP Joint Subcommittee on Aquaculture 1996).

Despite general acceptance about the importance of sustainability, there are no universal criteria for defining sustainable aquaculture enterprises. The aquaculture industry has attempted to address this lack of consensus in a number of ways. In recent years, conferences of the World Aquaculture Society (WAS) have devoted extensive attention and educational efforts to sustainability (Table 1) (Bardach 1995; Browdy and Hopkins 1995; Tidwell 1995). The Food and Agriculture Organization's (FAO) Fisheries Department recently published a Code of Conduct for Responsible Fisheries with criteria for aquaculture development (D'Abramo and Hargreaves 1997). The Aquaculture Sustainability Action Plan (ASAP), a collaborative effort of the Asian Development Bank and the Net- 
Table 1. Keynote topics from World Aquaculture Society meetings, 1985-1998.

\begin{tabular}{|c|c|}
\hline Year & Topic \\
\hline 1985 & The Challenge and Potential of Aquaculture \\
\hline 1986 & Agricultural Research Service and Aquaculture \\
\hline 1987 & Managing the Development of Aquaculture Fisheries \\
\hline 1988 & East Meets West \\
\hline 1989 & Towards Professionalism in Aquaculture \\
\hline 1990 & $\begin{array}{l}\text { Global Bivalve Shellfish Introductions: Implications for Sustaining a Fishery or } \\
\text { Strong Potential for Economic Gain }\end{array}$ \\
\hline 1991 & $\begin{array}{l}\text { Turn of the Millennium Aquaculture: Navigating Troubled Water or Riding the } \\
\text { Crest of the Wave }\end{array}$ \\
\hline $1992^{1}$ & Growing Towards the $21^{\text {st }}$ Century \\
\hline $1993^{1}$ & From Discovery to Commercialization \\
\hline $1994^{1}$ & Silver Anniversary: 25 Years of Science and Service \\
\hline $1995^{2}$ & PACON: Sustainable Aquaculture \\
\hline $1995^{1}$ & Quality Products: Quality Environments \\
\hline $1995^{3}$ & Swimming Through Troubled Waters \\
\hline $1996^{1}$ & East Meets West \\
\hline $1997^{1}$ & Linking Science to Sustainable Industry Development \\
\hline $1998^{1}$ & Mariculture at a Crossroads: Lessons of the Past and Visions of the Future \\
\hline $1998^{1,4}$ & Aquaculture Development with Sustainability \\
\hline \multicolumn{2}{|r|}{$\begin{array}{l}1 \text { Theme of meeting } \\
2 \text { Pacific Congress on Marine Science Technology } \\
{ }^{3} \text { Special WAS session on shrimp farming. } \\
{ }^{4} \text { Latin American Chapter of World Aquaculture Society }\end{array}$} \\
\hline
\end{tabular}

work of Aquaculture Centers in the Asia-Pacific region, recommended policies to promote responsible aquaculture (New 1996). All of these efforts, however, have lacked specific guidance on the implementation of new technologies or measures of their performance. Because they have been primarily qualitative in their approach, sustainability policy studies have been criticized for ignoring the sociopolitical context of aquaculture in specific regions (Edwards et al. 1990). 
Perhaps nothing has impeded progress toward specific definitions and methods more than the multi-faceted nature of sustainability. As public concern over the use of natural resources for economic activity grows, the aquaculture industry will need to coordinate resource use in ways that fulfill multiple, and sometimes conflicting, objectives (Pullin et al. 1993). This study investigates whether diverse aquaculture interest groups can collectively agree on ways to coordinate this resource use by developing goals and indicators of aquaculture sustainability. Specifically, this study used aquaculture experts from the production, research, regulatory and public interest sectors to identify and weight a broad range of indicators of aquaculture sustainability in the southeastern United States.

\section{Sustainability and Aquaculture}

The 1987 World Commission on Environment and Development (The Brundtland Commission) popularized the idea of sustainable development with a report that called for meeting the needs of the present generation without compromising the needs of future generations (Serageldin and Steer 1994). Since that time, numerous definitions of sustainability have been proposed. In general, the definitions describe sustainable systems as those that are "... productive, socially relevant, profitable, and environmentally compatible while making environmentally sound use of resources, not diverting or replacing resources that may be used in a more productive way, and not degrading the environment and jeopardizing the livelihood of future generations ... " (Asian Institute of Technology 1994). With such a broad and qualitative definition, it is not surprising that some have questioned whether sustainability is a bounded concept with measurable goals and objectives (Hammond et al. 1995). Instead, sustainability could be viewed as an infinite continuum where the focus is on progressing toward a goal that is itself shifting through time. If this latter view is correct, measures of sustainability will be intimately linked to technological, economic and social development.

Sustainability issues have rapidly become an important priority in aquaculture. Aquatic production technologies of the last two decades featured improvements in feed formulation, nutrition, water chemistry, disease prevention and treatment, and selection for 
commercially desirable traits. Although new production methods resulted in higher yields, they also were associated with considerably higher rates of resource use compared with traditional aquaculture methods. As a result, externalities associated with aquaculture production have become increasingly evident, and the industry faces public criticism over effluent discharges, threats to genetic diversity and destruction of estuarine habitats (Brown et al. 1994; Landesman 1994). In the United States, producers have encountered opposition from environmentalists about issues such as aquifer depletion and wetlands displacement, while rapid development of global estuarine habitats for shrimp farming has resulted in widespread disease and resource depletion (Rosenthal 1994). Additional conflicts have arisen where industrial aquaculture alters social institutions, such as when traditional employment in natural fisheries is displaced by estuarine aquaculture developments (Bailey, Jentoft, and Sinclair 1996). Many of these problems have led to disputes about the longterm ecological, sociological and economic viability of aquaculture industries.

\section{Policy Challenges}

Given its many facets, attempts to globally define sustainable aquaculture may be impractical. The first challenge presented by the sustainability concept is the need to consider unlike disciplines and objectives. Although definitions of sustainability are often internally inconsistent, they do share one common theme: sustainable systems are invariably defined by the need for simultaneous consideration of economic, environmental and sociological objectives (Figure 1). This multidisciplinary approach to describing sustainability has become widely accepted, with definitions of sustainability based solely on economics or ecology being heavily criticized (Serageldin et al. 1994; Hammond et al. 1995); however, only recently have scientists begun to integrate these three disciplines into working models of sustainability. The immediate challenge represented by such integration is the difficulty of simultaneously reconciling three disciplines with different conventions, languages and units of measurement.

Evaluations of aquaculture sustainability also depend on geographic and operational context. Context ultimately influences 


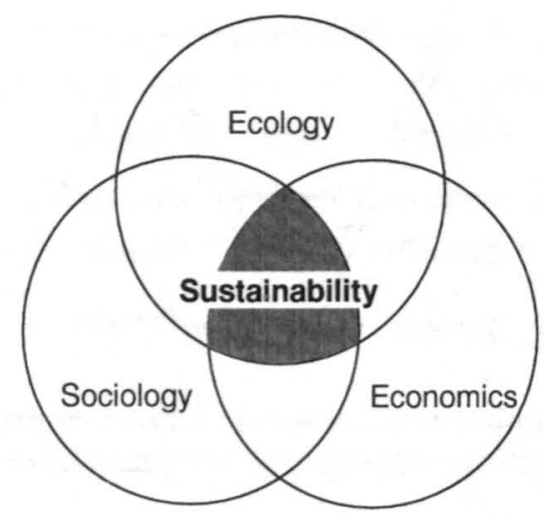

Figure 1. Depicting sustainability as the intersection of three disciplines: ecology, economics and sociology. In this conceptual model, the existence of a sustainable production technology depends on the simultaneous overlap of ecological, sociological and economic sustainability. Many current technologies may fail to satisfy one or more of these sustainability characteristics, or they may satisfy them only simultaneously with very specific circumstances.

environmental, economic and sociological dimensions while determining the degree to which site-specific information can be generated. As geographic and operational context narrows, the specificity of resulting information increases even as the range of application for this information decreases (Figure 2). ${ }^{1}$ Given the current understanding of sustainability concepts, regional evaluations may be more appropriate for producing useful objectives and indicators. Such regional investigations could focus on alternative ways to reduce water usage, reduce the animal-protein fraction of feeds and increase profit.

\footnotetext{
${ }^{1}$ For example, evaluations of aquaculture sustainability using a broad-scale, global approach are often issue based, resulting in qualitative goals with little specificity. Such goals include qualitative mandates like enhancing economic viability without jeopardizing human rights or environmental integrity. Conversely, assessments of aquaculture sustainability may result in data and parameters too specific for industry-level application, as when local recommendations suggest limiting annual water use to a specific percentage of total farm volume for channel catfish grow-out systems because of local aquifer conditions.
} 


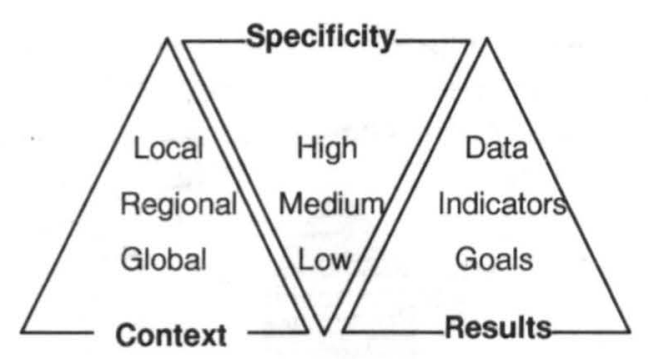

\section{Figure 2. The relationship and trade-offs among context, specificity and results in developing expressions for aquaculture sustainability.}

Although the recent interest in aquaculture sustainability has taken many forms, conflict and polarization of opinion have often punctuated the dialogue. Nevertheless, input from all stakeholder groups is required for objective definition and evaluation of sustainability, as well as for assuring that potential solutions are given an opportunity to work (Kazmierczak and Hughes 1997). At least four major stakeholder groups exist in aquaculture: 1) commercial producers, 2) aquaculture researchers and extension personnel, 3) state and federal regulatory officials and 4) members of non-governmental organizations. These four groups often hold widely disparate and sometimes volatile opinions concerning the extent to which sustainability concepts should shape aquaculture practice and policy. The perspective of one session's moderator on aquaculture sustainability equated the entire experience to a conflict resolution process, suggesting that consensus on goals and implementation strategies will not arise unless care is taken to include all viewpoints in the process (Hargreaves 1997).

The challenges encountered when trying to integrate disciplinary perspectives, geographic and operational context and stakeholder conflict-into a comprehensive and workable definition of sustainability are not trivial. No widely accepted method exists for overcoming these challenges and building consensus-based expressions of sustainability. The use of quantitative indicators, however, provides information to the process in a more concrete way than qualitative rhetoric, and indicators have a history of use in public policy analysis. Because indicators provide information in a simplified, concise format, they may be better suited for use in consensus 
formation than complicated statistics or data. In addition, the identification of suitable indicators is the first step in the development of a broad-based, multi-criteria index of sustainability.

Multi-criteria evaluation methods can be used to describe the subtle impacts of development alternatives not wholly captured by direct, market-based measures (Nijkamp, Rietveld, and Voogd 1990). In the context of sustainability, such an analysis could be used hypothetically to evaluate the progress toward economic, environmental and sociological optima. By varying assumptions such as project size, location, technology and intensity, a multi-criteria analysis could be used to isolate the common ground and trade-offs between the economics, ecology and sociology of various scenarios. The multi-criteria approach, however, requires the cooperation of qualified experts and decision-makers to identify and rank various index components (Vincke 1992, Hammond et al. 1995). This study focuses on the first stage of index development by employing a consensus-building technique to identify and weight indicators of aquaculture sustainability.

\section{Data and Methods}

A Delphi survey, which is a method for systematically developing a consensus opinion among experts, was used in this study. The Delphi approach originated at the Rand Corporation in 1948 as a means of short-term forecasting and consensus building by Cold War strategists (Sackman 1975). Applications of this technique vary greatly, ranging from business forecasting to fisheries management (Zuboy 1981). Walter and Reisner (1994) conducted a Delphi survey of agricultural scientists to develop a consensus on the general definition of sustainable agriculture. Results of that study revealed a preference among the respondents for the development of specific environmental management technologies as a means of becoming more sustainable.

The Delphi survey approach is based on four assumptions: 1) expert opinion is a valid input to inexact areas of research, 2) a consensus of experts is better than the opinion of a single expert, 3) preserving an expert's anonymity avoids problems with follow-theleader bias and 4) anonymity corrects for most of the inherent 
opinion biases. In its standard form, the survey process involves iterative questionnaires administered to individual experts in a manner protecting the anonymity of their responses. Feedback to the respondents between survey rounds allows participants to reevaluate their responses based on new information provided by the respondent group as a whole and may lead to response convergence, or a consensus of opinion, even among groups that initially hold widely disparate views (Sackman 1975). The survey process is generally terminated based on ad hoc reasons (time/budget constraints, qualitative lack of progress toward further consensus) or statistical convergence measures (Schmidt 1997).

\section{Survey Specifics}

The panel of expert stakeholders in this study consisted of aquaculture producers, researchers and extension personnel, regulatory authorities and non-governmental organizations (NGO). The names of producers with at least three years experience with warmwater species were collected from state extension and research personnel, as well as through other contacts. Production sites ranged from coastal to inland, with extensive or intensive production methods. University researchers and extension agents experienced in various aquaculture-related fields were included. The biological and mechanical areas of aquaculture were well represented, but only a few individuals specializing in the economic and sociological aspects of the industry could be identified. Governmental authorities included state and federal officials with experience in aquaculture activities in the southeastern United States. Specific duties of these individuals encompassed policy formation, regulations, enforcement, funding and promotion. While non-governmental organizations (NGOs) have become active in aquaculture issues in recent years, participation in this Delphi survey was restricted to NGO representatives who had knowledge of warm-water aquaculture in the southeastern United States. Overall, participation was limited to individuals working in Texas, Oklahoma, Arkansas, Louisiana, Mississippi, Tennessee, Kentucky, Alabama, Georgia, Florida, South Carolina, North Carolina and Virginia. As with any Delphi survey, composition of the expert panel was subject to selection bias. In this study, an interdisciplinary committee provided guidance for selec- 
tion, and participation ratios were developed to reflect the proportion to which experts from each group were represented in the southeastern United States. In addition, efforts were made to solicit participation in a manner reflecting the geographic concentration of aquaculture stakeholders in the Southeast; however, prior consideration could not account for the possibility of differential response rates.

The Delphi process used in this study consisted of three rounds conducted between September 1997 and May 1998. A preliminary questionnaire (round-1, or Rl) was made available to potential respondents via postal mail and the World Wide Web. ${ }^{2}$ Participation was invited via direct telephone contact. In $\mathrm{Rl}$, panel members were asked individually to list measurable indicators and preferences in three separate categories: economic, environmental and sociological sustainability. This information was used to form a follow-up questionnaire (round-2, or $\mathrm{R} 2$ ) requesting that respondents assign weights to specific indicators and provide additional preferencerelated information. Results of R2 were summarized and returned to the panel with a request to revise individual responses in light of the aggregate group response. This final round, round-3 (R3), saw considerable convergence of opinion and the development of consensus, not only on the relative importance of economic, environmental and sociological considerations in defining sustainability, but also on the relative importance of specific, measurable indicators of sustainability. Although further survey rounds may have led to a greater degree of convergence, nonparametric statistical measures (discussed below) suggested that the marginal benefits of these efforts would be small.

\footnotetext{
${ }^{2}$ Survey questionnaires and general information used in the survey process are available from the authors or can be accessed via the World Wide Web at http:www.agecon.Isu.edu/aquadelphi/survey.pdf.
} 


\section{Nomparametric Metbods}

Data collected in the Delphi survey represented the individual's opinion about the importance of a particular sustainability category or indicator. Such weightings along a 0 percent to 100 percent scale can be defined as cardinal because they explicitly express a degree of preference. Cardinal rankings, however, also imply a set of ordinal rankings that can be analyzed using non-parametric statistics (Conover 1971). Three non-parametric, rank correlation methods were used in this study to identify the presence of rank patterns, rank convergence and rank consensus in the Delphi survey data. These methods were Freidman's test, Kendall's W test and the Distance Metric test.

Freidman's test allows nonparametric analysis of data that does not conform to parametric assumptions about normality and homoscedasticity (Zar 1974). Conceptually, it employs a randomized block experimental design where data consist of $b$ mutually independent $a$-variate random variables $\left(\mathrm{X}_{i 1}, \mathrm{X}_{i 2}, \ldots, \mathrm{X}_{i a}\right)$ called $b$ blocks, $i=1,2, \ldots, b$. The data within each of the $b$ blocks are assigned ranks, which are summed for each of $a$ groups, each rank sum being denoted as $R_{i}$. The test statistic; $\chi_{\mathrm{r}}^{2}$, is calculated as:

$$
\chi_{r}^{2}=\frac{12}{b a(a+1)} \sum_{i=1}^{a} R_{i}^{2}-3 b(a+1)
$$

Critical values for the test statistic can be calculated by the equation

$$
\chi_{\alpha,(a-1)}^{2}=\frac{(1.64+\sqrt{2(a-1)-1})^{2}}{2}
$$

If tied ranks are present, then equation (1) can be reformulated as

$$
\left(\chi_{r}^{2}\right)_{c}=\frac{\sum_{i=1}^{a} R_{i}^{2}-\frac{\left(\sum_{i=1}^{a} R_{i}\right)^{2}}{a}}{\frac{b a(a+1)}{12}-\frac{\sum T}{a-1}}
$$


where the correction factor for tied ranks $(\Sigma T)$ is

$$
\sum T=\frac{\sum_{i=1}^{m}\left(t_{i}^{3}-t_{i}\right)}{12}
$$

with $t_{i}$ being the number ties in the $i$ th group of ties and $m$ the number of groups of tied ranks.

Freidman's test can be applied to Delphi survey data to determine whether rank patterns exist in the data. Freidman's null hypothesis is that each ranking of the random variables within a block is equally likely (or that the treatments have identical effects). The alternative hypothesis is that at least one of the treatments yields larger observed values than at least one other treatment. Thus, Freidman's test cannot identify the actual rankings, only whether some type of ranking appears to exist. Other shortcomings of Freidman's test include its propensity for rejection of the null hypothesis in the presence of slight rank correlation and the fact that the test yields no information on the degree of consensus within ranks.

Schmidt (1997) recommended the use of Kendall's statistic of concordance $(W)$ for evaluating the degree of rank convergence (consensus) in Delphi surveys. Kendall's $W$ is given by

$$
W=\frac{12}{b^{2} a(a+1)(a-1)} \sum_{i=1}^{a}\left(R_{i}-\frac{b(k+1)}{2}\right)^{2}
$$

where $k$ is the number of possible ranks. A comparison of Kendall's $W$ with Freidman's $\chi^{2}$ in equation (1) yields

$$
W=\frac{\chi_{r}^{2}}{b(a-1)}
$$

Confined to the $0-1$ interval, Kendall's $W$ can be interpreted as a measure of consensus in rankings rather than an actual test statistic, where $W$ provides information on the degree of consensus and the associated level of confidence in the expressed ranks. 
Used together, Freidman's $\chi_{\mathrm{r}}^{2}$ and Kendall's $W$ can identify the existence of rank correlation and rank convergence, but these calculations provide no information on the actual order in which ranks occur. Such ordering could be calculated as simple mean ranks, but mean ranks may fail to identify the consensus ranking that best agrees with all individual respondent rankings. Intrinsic to this problem is the actual measure of agreement or disagreement between individual rankings. Disagreement between individual rankings can be calculated by a distance metric approach whereby the consensus ranking is analyzed through a linear program (LP) procedure that minimizes the absolute distances between observed and possible ranks. In relatively simple applications, such as the one formed in this study, a heuristic can be used in place of a formal LP. As an example of how the distance metric is determined, consider the $\mathrm{R} 3$ rankings by all respondents of the three sustainability categories (environmental, economic and social). A $3 \mathrm{X} 3$ distance matrix $(A)$ is derived from the sums of $9 n$ absolute differences between observed and possible ranks (1st, 2 nd and 3rd) for each sustainability category. In this study, the resulting distance matrix of absolute values $(B)$ was evaluated using a linear assignment procedure (Cook and Seiford 1978) programmed in Microsoft ${ }^{\circledR}$ Excel 97. The resulting consensus rank matrix $(C)$ is read row by row to yield a consensus rank order. A detailed description of this process is beyond the scope of this report, but a complete explanation of the formulation and use of distance functions is provided in Cook and Seiford (1978) and Caffey (1998).

\section{Descriptive Results}

Participation rates in the survey were higher than originally anticipated (Table 2). Of the 163 individuals who initially agreed to participate, 121 replied to $\mathrm{Rl}$ for a response rate of 75 percent. By $\mathrm{R} 3$, the retention rate had increased to 94 percent, with 104 individuals participating. The distribution of responses across stakeholder categories changed only slightly between Rl and R3.

Figure 3 depicts the regional distribution of the Delphi survey respondents. Despite a reduction in the number of respondents between rounds, the relative geographic distribution of stakeholders remained unchanged. Reflecting the geographic location of aqua- 
Table 2. Participation statistics for the Delphi survey

\begin{tabular}{lccc}
\hline & Round 1 & Round 2 & Round 3 \\
\hline Number of Contacts & 163 & 121 & 111 \\
Number of Responses & 121 & 111 & 104 \\
Overall Response Rate (\%) & 75 & 92 & 94 \\
Distribution of Responses (\%) & & & \\
$\quad$ Producers & 31 & 29 & 29 \\
$\quad$ Research/Extension & 18 & 41 & 39 \\
$\quad$ Governmental & 16 & 18 & 19 \\
NGO & & 13 & 13 \\
\hline
\end{tabular}

culture production in the southeastern United States, most respondents were from Mississippi, Alabama and Louisiana. These states have major aquaculture sectors dedicated to channel catfish and crawfish production. A range of 5-10 respondents were from Texas, Arkansas, Florida, North Carolina and South Carolina, and 1-5 respondents represented Oklahoma, Tennessee, Kentucky, Virginia and Georgia.

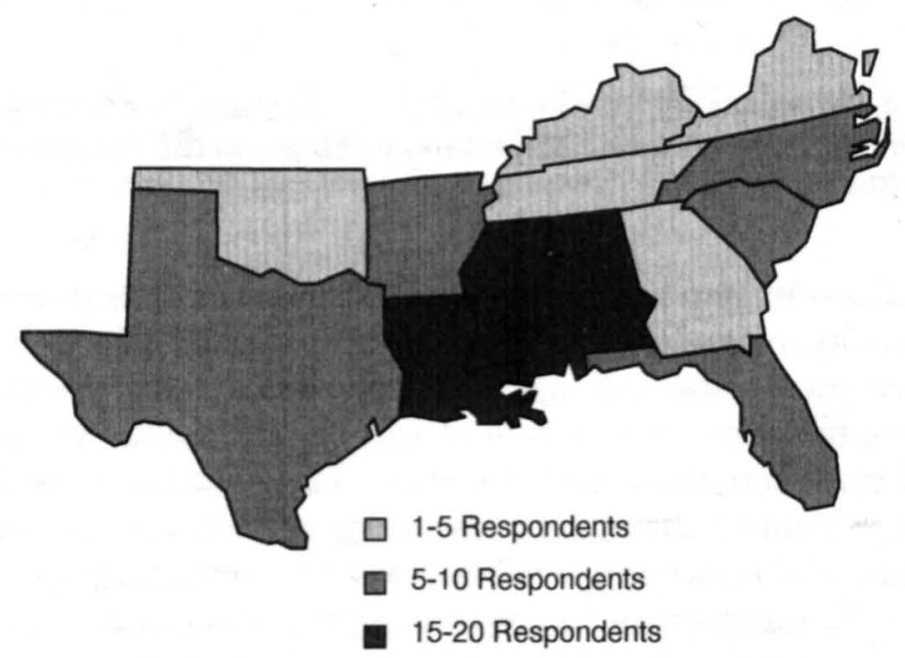

Figure 3. Regional distribution of respondents in the Delphi survey of aquaculture sustainability in the southeastern United States. 
Participants were asked to identify the primary aquaculture commodity they produced, researched, regulated or monitored (Figure 4). Channel catfish were associated with 34 percent of the respondents. Interestingly, the second largest aquaculture commodity of primary interest was shrimp/prawns. The 15 percent represented by this category includes only a small number of coastal shrimp farmers in Texas and South Carolina, with the bulk of the group composed of researchers, regulators and NGO members involved in shrimp production. Other commodities of primary interest were associated with 5 percent to 7 percent of the respondents and included crawfish, redfish, baitfish, oysters and clams, hybrid striped bass and tilapia. A smaller number of respondents (2 percent to 3 percent) listed sport fish and ornamentals.

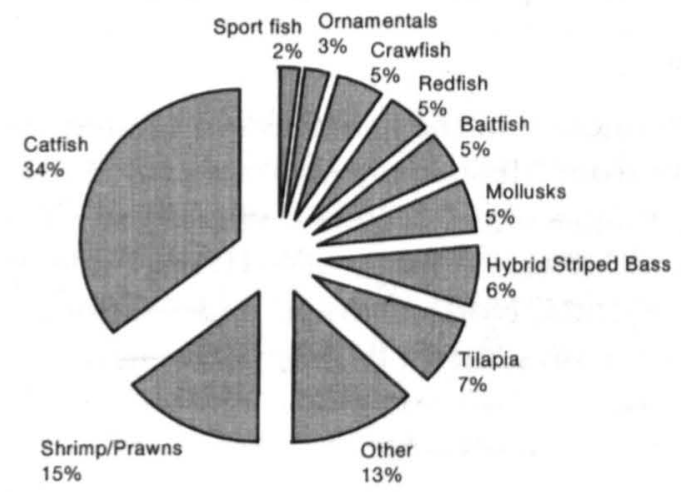

Figure 4. Primary species of interest for respondents participating in the Delphi survey of aquaculture sustainability in the southeastern United States.

Participants were asked to identify the areas that best described their activity in aquaculture (Figure 5). More than half of the panel indicated production and management as their primary activity, reflecting the large contribution of aquaculture producers, researchers and extension agents to the survey. Only a few panelists ( 2 percent) identified themselves as working primarily in the area of sociology. The remaining areas included administration and policy ( 4 percent), nutrition and feeds ( 5 percent), water quality and aquaculture engineering ( 6 percent), reproduction and genetics ( 7 percent), conservation and fisheries management ( 7 percent) and economics ( 8 percent $)$. 


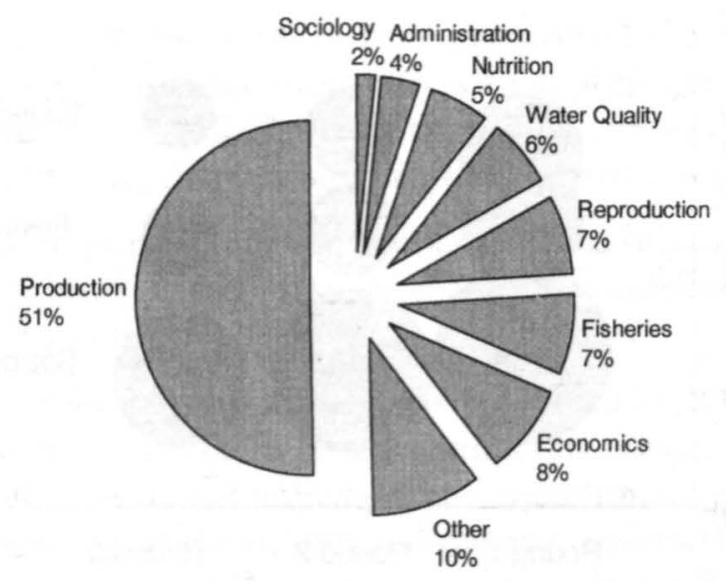

Figure 5. Primary areas of work for respondents participating in the Delphi survey of aquaculture sustainability in the southeastern United States.

\section{Disciplinary Weights}

A maintained hypothesis of this study was that Delphi participants would find it easier to define sustainability indicators if the interdisciplinary nature of the problem was temporarily simplified. Thus, respondents were allowed to partition their responses among traditional disciplines, thereby facilitating indicator identification and conventions of measurement. Once the discipline-based individual indicators were developed, a process was needed to allow future aggregation of the indicators. Such aggregation usually requires delineating the relative importance of each individual indicator and each indicator discipline (environmental, economic and sociological).

$\mathrm{Rl}$ respondents indicated a weighting preference of 44 percent for economic sustainability, 36 percent for environmental sustainability and 20 percent for social sustainability (Figure 6). The coefficient of variation $(\mathrm{CV})$ on the responses, used to denote the relative level of consensus on the weightings, suggested there was a wide range of opinion concerning the importance of each type of sustainability and significant overlap among the disciplinary categories. In keeping with the Delphi process, $\mathrm{R} 2$ and $\mathrm{R} 3$ respondents reviewed values from previous rounds and were given the opportunity to adjust their individual weightings. By R3, mean weightings had increased by 5 percent for economic sustainability, and fallen 2 


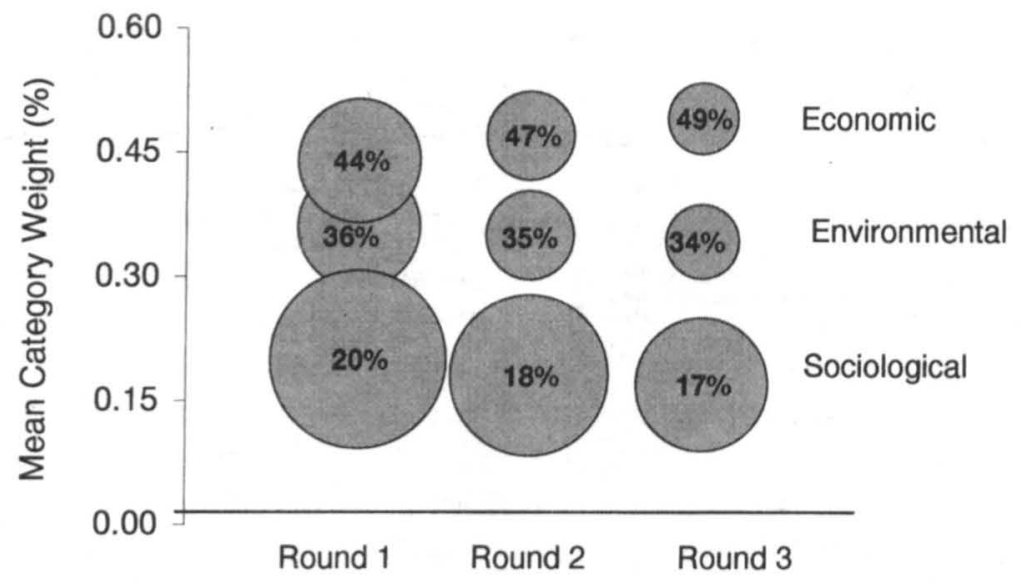

Figure 6. Mean Respondent Preferences for Environmental (E), Economic (\$) and Sociological (S) Sustainability for Rounds 1-3 of the Delphi survey. (Circle size denotes the coefficient of variation; value in the circle denotes the mean weight.)

percent and 3 percent for environmental and sociological sustainability, respectively. While the magnitude of these changes was small, $\mathrm{CV}$ values suggest that opinions about the relative importance of the different kinds of sustainability significantly converged over the three rounds, effectively eliminating the overlap in weighting among the disciplinary categories. Small CVs for economic and environmental disciplines imply greater consensus on their relative importance within the context of aquaculture sustainability. The relatively large $\mathrm{CV}$ for sociological sustainability suggests greater contention over the importance of social considerations.

\section{Indicators}

$\mathrm{Rl}$ respondents were encouraged to submit an unlimited list of potential indicators while adhering to three basic rules:

1) Stay in context. The context for the survey was regional, pertaining only to production-level aquaculture in the southeastern United States, including coastal or inland culture systems with intensive or extensive management.

2) Use categories. Respondents were instructed to list indicators separately for the disciplinary categories of environmental, economic and sociological sustainability. 
3) Be concise. Respondents were requested to be as concise as possible, listing measurable indicators with appropriate units $(\mathrm{kg} / \mathrm{ha}$, $\mathrm{mg} / \mathrm{l}$ ) and the general direction of change (increase/decrease) that would be needed to enhance sustainability in that category.

The high response rate and number of items submitted as potential indicators $(1,622)$ suggest that these guidelines did not hinder the respondents.

More than 80 percent of the items submitted by $\mathrm{Rl}$ respondents met the criteria of specificity and measurability. Given the extremely large number of potential indicators and the ultimate goal of a consensus ranking for them, only indicators mentioned by at least 20 percent of any single stakeholder group were used in R2. This 20 percent cutoff was chosen to maintain a wide variety of respondent opinions while simultaneously reducing the set of possible indicators that had to be considered in subsequent rounds. After parsing, the items were mapped into aggregate indicator categories. ${ }^{3}$

This aggregation yielded 31 indicators of aquaculture sustainability, composed of 12 environmental, 10 economic and nine social indicators. ${ }^{4}$ In R2, the indicators were randomly listed within their disciplinary category along with the frequency with which they were mentioned in $\mathrm{Rl}$. Given this information, respondents were asked to weight each indicator ( 0 percent to 100 percent) according to their perception of its relative importance within a particular disciplinary category. In R3, respondents were provided the mean weights and the 50 percent R2 weighting range for each indicator. Respondents were then given the choice to either accept the mean value as representing their final weighting or suggest a change in the value. Table 3 lists each of the 31 aggregate indicators, the respondents' opinions concerning the direction of change to increase sustainability, and the mean and standard deviation of the weights given by respondents in $\mathrm{R} 2$ and $\mathrm{R} 3$.

\footnotetext{
${ }^{3}$ Aggregation lumped similar respondent indicators based on theoretical or measurement criteria. For example, responses that suggested "net revenue," "profit" or "income" were aggregated into a single category.

${ }^{4}$ Twelve major indicators emerged from the 610 items submitted in R1 under the environmental category. Of the 568 items submitted in R1 as potential measures of economic sustainability in aquaculture, 10 aggregate indicators were identified. Finally, of the 444 items submitted in R1 as potential measures of social sustainability in aquaculture, nine aggregate indicators were constructed.
} 
Table 3. Categories and indicators of aquaculture sustainability from a Delphi survey in the southeastern United States.

Indicator

Code and

Respondent Weightings (0-100\%)

Direction of

Increasing

Sustainability Definition*

Round 2

Round 3

(mean/std. dev.) (mean/std. dev.)

\begin{tabular}{lll}
\multicolumn{3}{c}{ Environmental Indicators (E) } \\
$\mathrm{E}_{1}$ & 1 & Quantity of land used \\
$\mathrm{E}_{2}$ & $\downarrow$ & Quantity of energy used \\
$\mathrm{E}_{3}$ & $\downarrow$ & Animal fraction of supplemental protein \\
$\mathrm{E}_{4}$ & 1 & Quantity of chemicals used \\
$\mathrm{E}_{5}$ & 1 & Quantity of water discharged \\
$\mathrm{E}_{6}$ & 1 & Biochemical oxygen demand in effluent \\
$\mathrm{E}_{7}$ & 1 & Supplemental feed protein used \\
$\mathrm{E}_{8}$ & 1 & Total ammonia nitrogen in effluent \\
$\mathrm{E}_{9}$ & 1 & Culture of non-indigenous species \\
$\mathrm{E}_{10}$ & $\downarrow$ & Total phosphorus in effluent \\
$\mathrm{E}_{11}$ & 1 & Production in natural wetlands \\
$\mathrm{E}_{12}$ & 1 & Suspended solids in effluent
\end{tabular}

$10.02 / 8.81$

$8.94 / 2.73$

$10.81 / 7.19$

$10.19 / 2.65$

$5.62 / 4.13$

$6.57 / 2.24$

$7.09 / 4.48$

$7.11 / 1.79$

$16.10 / 8.89$

$15.31 / 2.52$

$9.54 / 4.62$

$9.89 / 1.68$

$5.85 / 3.99$

$6.05 / 1.41$

$8.81 / 4.88$

$8.89 / 1.46$

$3.86 / 3.51$

$3.70 / 2.05$

$7.85 / 4.39$

$8.47 / 1.94$

$6.53 / 4.52$

$6.99 / 2.14$

$7.91 / 4.60$

$7.95 / 1.56$

\section{Economic Indicators (\$)}

$\begin{array}{lll}\$_{1} & 1 & \text { Gross revenue } \\ \$_{2} & 1 & \text { Total variable production cost } \\ \$_{3} & 1 & \text { Fixed cost of production } \\ \$_{4} & 1 & \text { Overall profit } \\ \$_{5} & 1 & \text { Return on investment } \\ \$_{6} & 1 & \text { Variability in annual profits } \\ \$_{7} & 1 & \text { Feed conversion ratio } \\ \$_{8} & 1 & \text { Cost of regulatory compliance } \\ \$_{9} & 1 & \text { Per capita consumption } \\ \$_{10} & 1 & \text { Market outlets }\end{array}$

$\begin{array}{rr}8.19 / 4.53 & 7.80 / 2.11 \\ 16.06 / 7.11 & 15.32 / 2.27 \\ 7.61 / 4.74 & 6.70 / 1.13 \\ 18.42 / 9.06 & 18.84 / 2.81 \\ 11.38 / 6.20 & 10.56 / 2.44 \\ 6.51 / 4.38 & 7.03 / 1.77 \\ 9.46 / 5.39 & 9.77 / 1.95 \\ 6.25 / 4.58 & 6.58 / 2.53 \\ 11.74 / 6.72 & 12.36 / 2.82 \\ 4.38 / 3.41 & 5.05 / 2.32\end{array}$

\section{Sociological Indicators (S)}

$\mathrm{S}_{1} \quad \mathbf{T} \quad$ Local consumption of product

$7.17 / 4.97$

$6.86 / 2.61$

$\mathrm{S}_{2} \quad \mathrm{~T}$ Use of local inputs

$\mathrm{S}_{3} \quad \mathrm{~T} \quad$ Value of job benefits

$10.59 / 5.9$

$10.76 / 2.36$

$6.57 / 4.39$

$7.31 / 1.22$

$\mathrm{S}_{4} \quad 1 \quad$ Worker safety

$7.45 / 5.35$

$7.88 / 1.42$

$\mathrm{S}_{5} \quad 1 \quad$ Local ownership

$13.63 / 7.76$

$13.96 / 2.28$

$\mathrm{S}_{6} \uparrow \quad$ Wage levels

$\mathrm{S}_{7} \mathrm{I}$ Jobs/employment

$15.20 / 7.07$

$15.50 / 2.16$

$19.45 / 11.7$

$18.05 / 4.42$

$\mathrm{S}_{8} \quad \downarrow \quad$ Competition with local industries

$4.92 / 4.09$

$4.73 / 1.64$

$\mathrm{S}_{9} \quad \mathrm{~T}$ Perception of local aquaculture industry

$15.02 / 9.41$

$14.96 / 1.64$

* The table includes an abbreviated definition of each indicator. See survey for a complete definition of each indicator: http://www.agecon.Isu.edu/aquadelphi/survey.pdf 


\section{Description of Indicators}

Two basic concepts appeared to have dominated the respondents' thinking when identifying environmental indicators resource use and environmental externalities (pollution). Resource use indicators included conservation of land, energy, protein, water and wetlands. Externality related indicators included recommendations to reduce chemical use, effluent biochemical oxygen demand, total ammonia-nitrogen, total phosphorus, suspended solids and the use of non-native species for aquaculture. The economic indicators focused on profitability, risk, efficiency and marketing issues. Profitability was represented by gross revenue, variable and fixed costs, overall profit and return on investment indicators. From an economist's perspective, overall profit might adequately represent all of these indicators, but the respondents' indicator structure was maintained across survey rounds even if it was somewhat redundant. Risk-related indicators included annual variability in profits and the cost of regulatory compliance. Feed conversion ratio (FCR) was included as an economic indicator, although many panelists also listed FCR as an environmental indicator. FCR is a unitless value and states nothing about the actual amount of feed used or its impact on the environment. Aquaculture operations with lower FCRs, however, can be said to have a greater degree of technical efficiency with respect to feed inputs. Marketing concerns were reflected in the economic indicators of per capita consumption and outlets.

The sociological indicators reflected concerns such as job availability, compensation rates, benefits and worker safety. Communitylevel concerns were represented by goals to increase the local consumption of the commodity, use of local inputs and local ownership. Overall, community-level objectives represented a desire to protect local industries and institutions from competition. While local perception of aquaculture may be difficult to measure, this indicator could feasibly be a function of registered complaints against a particular aquaculture sector or farm. 


\section{Indicator Weightings}

Overall, mean indicator weights did not change significantly between R2 and R3, but the variation about the means decreased significantly. The average CV across all indicators for R2 was 0.63 , indicating a fairly large difference of opinion about the relative importance of the indicators. The average CV dropped to 0.25 by R3, however, suggesting a general movement toward consensus between rounds. Of course, $\mathrm{CV}$ values for individual indicators varied considerably.

Figure 7 depicts R3 weights and relative CV values for individual environmental, economic and sociological indicators. The indicators for water discharge $\left(\mathrm{E}_{5}\right)$, quantity of energy used $\left(\mathrm{E}_{2}\right)$, variable costs $\left(\$_{2}\right)$, profit $\left(\$_{4}\right)$, wages $\left(S_{6}\right)$ and jobs $\left(S_{7}\right)$ had the highest mean weights in their respective categories. On the other end of the spectrum were those indicators that had low mean weights and relatively large CV values, suggesting both low importance and a greater amount of disagreement over the actual level of importance. In the economic and sociological categories, market outlets $\left(\$_{10}\right)$ and local competition $\left(S_{8}\right)$ represent two such indicators. The most prominent example of this type of indicator was reducing the culture of non-native species $\left(\mathrm{E}_{9}\right)$. This indicator had the lowest mean weight and highest $\mathrm{CV}$ among all 31 indicators, indicating low importance and relatively little agreement on the level of importance to sustainability.

While the tabular and graphical description of the data gives an overview of respondent opinions about sustainability, statistical analysis is required to identify those indicators that are quantitatively more important in determining perceived aquaculture sustainability. The non-random nature in which Delphi survey panels are identified, however, typically precludes the use of parametric statistics for data analysis. In these cases, quantitative analysis must turn to nonparametric statistics. 

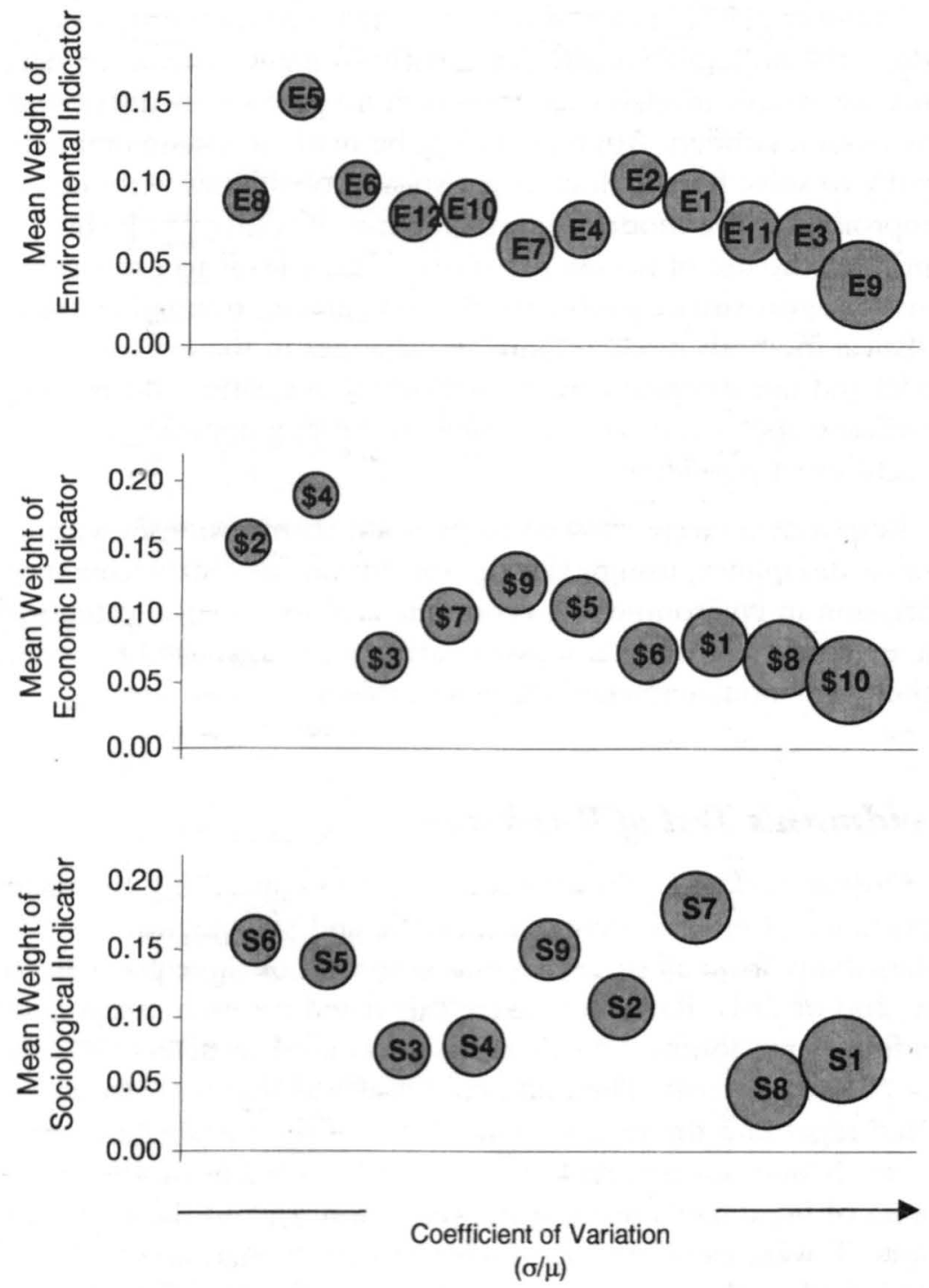

Figure 7. Mean Weights and Coefficients of Variation for Aquaculture Sustainability Indicators Identified in Delphi Survey of Stakeholders in the Southeastern United States (indicator codes defined in Table 5). 


\section{Ordinal Ranking Analysis}

Conover (1971) pointed out that while parametric statistics address the probabilities associated with normally distributed data, many reasonable models exist for which no probability distributions have been identified. Attempts might be made to change models slightly to solve for the desired statistical probabilities without compromising the model's approximation of reality. With this approach, the use of parametric statistics only leads to exact solutions for approximate problems. By comparison, nonparametric statistical methods rarely require any changes in the experimental model and use straightforward methods of evaluation. Such nonparametric approaches are equivalent to finding approximate solutions to exact problems.

Respondents were allowed to partition their responses within familiar disciplines, using existing conventions of measurement and expression in environmental, economic and sociological categories. The cardinal weightings discussed earlier were converted to ordinal rankings for nonparametric analysis (Table 4).

\section{Freidman's Test of Rankings}

Ordinal rankings of respondent opinions concerning the relative importance of environmental, economic and sociological sustainability from all survey rounds consisted of three possible ranks (1st, 2nd or 3rd). Rank sums were calculated for each category, and Freidman's randomized block analysis was used to detect the existence of rank patterns. The null hypothesis was that no patterns existed regarding the relative importance of the sustainability categories. Numerous tied ranks in the data required using the modified version of Freidman's test statistic (equation 3), and the correction factors $\mathrm{T}$ were calculated for each test case (equation 4 ). Tests included all survey respondents, resulting in blocks $(b)$ of 120,110 and 104 for rounds 1,2 and 3, respectively. Freidman's test also was performed separately on the revealed rankings within each stakeholder group, for a total of 15 tests (Table 5). Consensus patterns were detected in every test, implying differences in the relative importance of the three sustainability categories. 
Table 4. Mean rankings for categories and indicators of aquaculture sustainability

\begin{tabular}{|c|c|c|c|c|}
\hline \multirow{2}{*}{$\begin{array}{l}\text { Indicator } \\
\text { Code }\end{array}$} & \multirow[t]{2}{*}{ Definition $^{*}$} & \multicolumn{3}{|c|}{ Ordinal Rank ${ }^{\star *}$} \\
\hline & & Round 1 & Round 2 & Round 3 \\
\hline \multicolumn{2}{|c|}{ Environmental Indicators } & 2 & 2 & 2 \\
\hline$E_{1}$ & Quantity of land used & & 6 & 5 \\
\hline $\mathrm{E}_{2}$ & Quantity of energy used & & 3 & 3 \\
\hline $\mathrm{E}_{3}$ & Animal fraction of supplemental prote & tein & 11 & 10 \\
\hline$E_{4}$ & Quantity of chemicals used & & 8 & 8 \\
\hline$E_{5}$ & Quantity of water used & & 1 & 1 \\
\hline$E_{6}$ & Biochemical oxygen demand in efflue & & 2 & 2 \\
\hline$E_{7}$ & Supplemental feed protein used & & 10 & 11 \\
\hline $\mathrm{E}_{8}$ & Total ammonia nitrogen in effluent & & 4 & 4 \\
\hline $\mathrm{E}_{9}$ & Culture of non-indigenous species & & 12 & 12 \\
\hline$E_{10}$ & Total phosphorus in effluent & & 5 & 6 \\
\hline$E_{11}$ & Production in natural wetlands & & 9 & 9 \\
\hline$E_{12}$ & Suspended solids in effluent & & 7 & 7 \\
\hline \multicolumn{2}{|c|}{ Economic Indicators } & 1 & 1 & 1 \\
\hline$\$$ & Gross revenue & & 6 & 6 \\
\hline$\$ \$_{2}$ & Total variable production cost & & 2 & 2 \\
\hline$\$_{3}$ & Fixed cost of production & & 7 & 8 \\
\hline$\$_{4}$ & Overall profit & & 1 & 1 \\
\hline$\$$ & Return on investment & & 3 & 4 \\
\hline$\$ \$_{6}$ & Variability in annual profits & & 8 & 7 \\
\hline$\$$ & Feed conversion ratio & & 5 & 5 \\
\hline$\$$ & Cost of regulatory compliance & & 9 & 8 \\
\hline$\$$ & Per capita consumption & & 4 & 3 \\
\hline$\$_{10}$ & Market outlets & & 10 & 10 \\
\hline \multicolumn{2}{|c|}{ Sociological Indicators } & 3 & 3 & 3 \\
\hline $\mathrm{S}_{1}$ & Local consumption of product & & 8 & 7 \\
\hline $\mathrm{S}_{2}$ & Use of local inputs & & 5 & 5 \\
\hline $\mathrm{S}_{3}$ & Value of job benefits & & 7 & 8 \\
\hline $\mathrm{S}_{4}$ & Worker safety & & 6 & 6 \\
\hline $\mathrm{S}_{5}$ & Local ownership & & 4 & 4 \\
\hline $\mathrm{S}_{6}$ & Wage levels & & 2 & 2 \\
\hline $\mathrm{S}_{7}$ & Jobs/employment & & 1 & 1 \\
\hline $\mathrm{S}_{8}$ & Competition with local industries & & 9 & 9 \\
\hline $\mathrm{S}_{9}$ & Perception of local aquaculture indus & stry & 3 & 3 \\
\hline
\end{tabular}

* Abbreviated definition, see the survey at: http://www.agecon.Isu.edu/aquadelphi/ survey.pdf for a complete definition of each indicator.

${ }^{* *}$ Rank of greatest importance $=1$. 
Table 5. Freidman's test for ranked aquaculture sustainability categories.

\begin{tabular}{|c|c|c|c|c|c|c|c|c|c|}
\hline & \multicolumn{3}{|c|}{ Participants (b) } & \multicolumn{3}{|c|}{ Correction Factor $\left(\mathrm{E}^{\top}\right)$} & \multicolumn{3}{|c|}{ Freidman's Statistic } \\
\hline & R1 & R2 & R3 & R1 & R2 & R3 & R1 & R2 & R3 \\
\hline All Respondents & 120 & 110 & 104 & 30 & 22 & 10 & 103 & 139 & 168 \\
\hline Producers & 36 & 33 & 30 & 7 & 7 & 2 & 45 & 48 & 52 \\
\hline Research \& Ext. & 42 & 48 & 41 & 12 & 10 & 4 & 43 & 73 & 69 \\
\hline Regulators & 25 & 18 & 20 & 7 & 4 & 1 & 21 & 20 & 37 \\
\hline NGO & 17 & 11 & 13 & 5 & 3 & 3 & 8 & 8 & 11 \\
\hline
\end{tabular}

* $a=3$ treatments (environmental, economic and sociological sustainability categories); $H_{0}$ (no rank patterns) rejected at $a=0.05$ when Freidman's test statistic is greater than the critical value 5.73 (equation 2). Note that $\mathrm{H}_{0}$ was rejected in all tests.

Freidman's test also was calculated within each of the three sustainability categories using the indicators as the treatments. Possible ranks included 1st-12th for environmental, 1st-10th for economic and 1st-9th for sociological indicators. As with the category tests, the null hypothesis was that no patterns existed regarding the relative importance of the indicators. Unlike the sustainability categories, individual indicators were not weighted until R2 and R3, and only 10 tests were conducted per category for a total of 30 tests. Results of the indicator tests are provided in tables 6-8. Consensus patterns were detected in every case, implying patterns in the ranking of indicators within the environmental, economic and sociological categories. 
Table 6. Freidman's test for ranked environmental indicators of aquaculture sustainability.

\begin{tabular}{|c|c|c|c|c|c|c|}
\hline & \multicolumn{2}{|c|}{ Participants (b) } & \multicolumn{2}{|c|}{ Correction Factor $\left(\mathrm{E}^{\top}\right)$} & \multicolumn{2}{|c|}{ Freidman's Statistic } \\
\hline & R2 & R3 & R2 & R3 & R2 & R3 \\
\hline All Respondents & 110 & 104 & 1082 & 451 & 290 & 723 \\
\hline Producers & 33 & 30 & 336 & 104 & 124 & 168 \\
\hline Research \& Ext. & 48 & 41 & 522 & 177 & 157 & 225 \\
\hline Regulators & 18 & 20 & 131 & 110 & 66 & 168 \\
\hline NGO & 11 & 13 & 94 & 60 & 30 & 76 \\
\hline
\end{tabular}

${ }^{\star} a=12$ treatments (indicators); $\mathrm{H}_{0}$ (no rank patterns) rejected at $\mathrm{a}=0.05$ when Freidman's test statistic is greater than the critical value 19.45 (equation 2). Note that $\mathrm{H}_{0}$ was rejected in all tests.

Table 7. Freidman's test for ranked economic indicators of aquaculture sustainability.

\begin{tabular}{|c|c|c|c|c|c|c|}
\hline 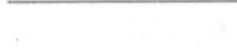 & \multicolumn{2}{|c|}{ Participants (b) } & \multicolumn{2}{|c|}{ Correction Factor $\left(\mathrm{E}^{\mathrm{T}}\right)$} & \multicolumn{2}{|c|}{ Freidman's Statistic } \\
\hline & R2 & R3 & R2 & R3 & R2 & R3 \\
\hline All Respondents & 110 & 104 & 443 & 282 & 432 & 698 \\
\hline Producers & 33 & 30 & 224 & 87 & 153 & 188 \\
\hline Research \& Ext. & 48 & 41 & 145 & 106 & 220 & 280 \\
\hline Regulators & 18 & 20 & 75 & 42 & 77 & 137 \\
\hline NGO & 11 & 13 & 51 & 47 & 37 & 81 \\
\hline
\end{tabular}


Table 8. Freidman's test for ranked sociological indicators of aquaculture sustainability.

\begin{tabular}{|c|c|c|c|c|c|c|}
\hline \multicolumn{2}{|c|}{ Participants (b) } & \multirow{2}{*}{$\frac{\text { Correction }}{\text { R3 }}$} & \multirow{2}{*}{$\frac{\text { Factor }\left(E^{\top}\right)}{R 2}$} & \multicolumn{3}{|c|}{ Freidman's Statistic } \\
\hline & R2 & & & R3 & R2 & R3 \\
\hline All Respondents & 110 & 104 & 371 & 162 & 291 & 678 \\
\hline Producers & 33 & 30 & 123 & 49 & 79 & 220 \\
\hline Research \& Ext. & 48 & 41 & 147 & 49 & 151 & 314 \\
\hline Regulators & 18 & 20 & 68 & 24 & 44 & 152 \\
\hline NGO & 11 & 13 & 34 & 42 & 29 & 106 \\
\hline
\end{tabular}

* $a=9$ treatments (indicators); $\mathrm{H}_{0}$ (no rank patterns) rejected at $\mathrm{a}=0.05$ when Freidman's test statistic is greater than the critical value 19.45 (equation 2). Note that $H_{0}$ was rejected in all tests.

\section{Kendall's Test for Convergence}

Kendall's W (equation 6) was calculated using the information generated during the calculation of Freidman's test. Figure 8 depicts the Kendall's $W$ for ranked preferences on the relative importance of environmental, economic and sociological categories of aquaculture sustainability. Schmidt (1997) provides a table for interpretation of Kendall's $W$ along its 0-1 interval (Table 9). Relatively small values of $\mathrm{W}$ indicate weak agreement and little or no confidence in the observed ranks; however, moderate to strong agreement ( $W$ between 0.5 and 0.7 ) was observed in $\mathrm{Rl}$ of the Delphi survey for all respondents and for the producer, research and extension, and regulator stakeholder groups. By the end of R3, rankings of all respondents in these three stakeholder groups had converged considerably, reaching a level of strong to unusually strong agreement with a very high confidence in rank structure. The NGO stakeholder group reached only weak to moderate agreement by the end of R3, however, with only low to fair confidence in the ranks.

Similar calculations of Kendall's $W$ were performed on the R2 and R3 ranked indicators of each sustainability category. Figure 9 depicts a considerable degree of rank convergence for environmental, economic and sociological indicators between R2 and R3. One notable exception is the level of agreement on the ranking of envi- 


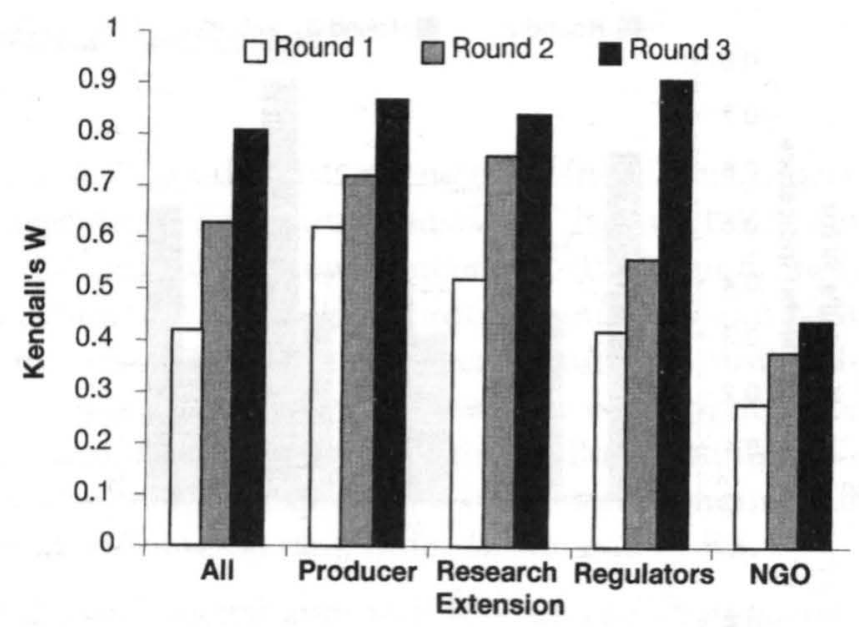

Figure 8. Kendall's coefficient of concordance (W) on ranked preferences for three subcategories of aquaculture sustainability (Environmental, Economic and Sociological).

ronmental indicators, which reached only fair confidence for the producer and research and extension stakeholder groups. It is worth reiterating that Kendall's $W$ detects only a level of agreement and states nothing about the actual order in which the indicators have been ranked. Values of $W$ can increase in response to agreement on both favorable and unfavorable indicators.

Table 9. Interpretation of Kendall's W(as adapted from Schmidt 1997).

\begin{tabular}{lcc}
\hline $\boldsymbol{W}$ & Interpretation & Confidence in Ranks \\
\hline 0.1 & Very weak agreement & None \\
0.3 & Weak agreement & Low \\
0.5 & Moderate agreement & Fair \\
0.7 & Strong agreement & High \\
0.9 & Unusually strong agreement & Very High
\end{tabular}



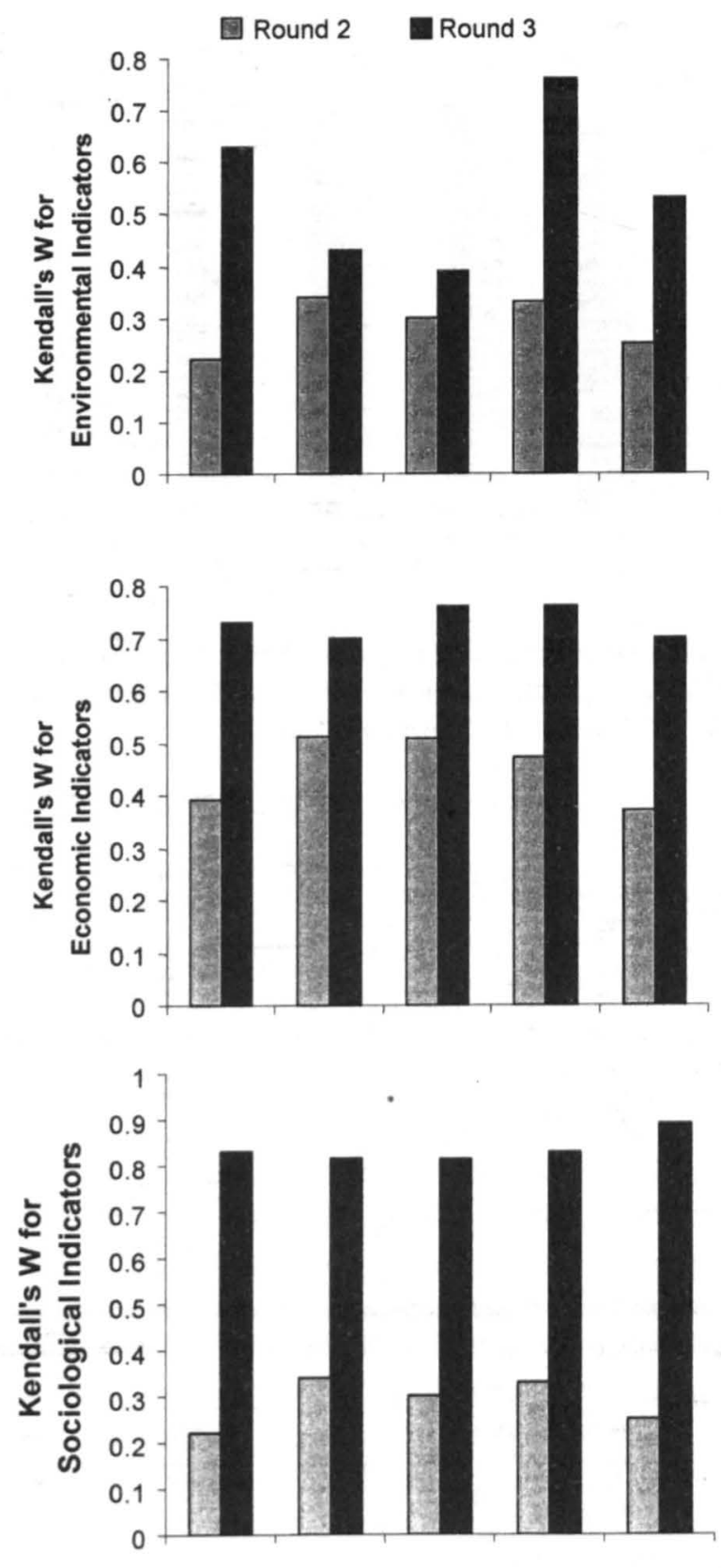

All Producer $\begin{aligned} & \text { Res/ Reg NGO } \\ & \text { Ext }\end{aligned}$

Figure 9. Kendall's coefficient of concordance $(W)$ on ranked indicators of three categories of aquaculture sustainability (Environmental, Economic and Sociological). 


\section{Consensus Rankings}

Table 10 shows the distance metric derived rank orders for the three categories of aquaculture sustainability in Rl-R3. During Rl and $\mathrm{R} 2$, the ordinal rankings generally followed an economic, environmental and sociological order. Regulatory and NGO groups initially expressed a preference for environmental sustainability as the most important category, followed by equal preferences for economic and sociological sustainability. But, with iterative Delphi feedback, stakeholders expressed a consensus economic, environmental and sociological rank order by the end of R3.

The distance metric approach was used to identify consensus rankings for the indicators within each sustainability category. For all responses aggregated together, the analysis required the sums $144 n, 100 n$ and $81 n$ absolute values to construct $12 \mathrm{X} 12,10 \mathrm{X1} 0$ and $9 \times 9$ matrices for environmental, economic and sociological catego-

Table 10. A distance metric derived rank order for environmental, economic and sociological categories of aquaculture sustainability.

\begin{tabular}{|c|c|c|c|c|c|c|}
\hline & Round 1 & & Round 2 & & Round 3 & \\
\hline Stakeholder & Rank & & Rank & & Rank & \\
\hline Group & $1^{\text {st }}, 2^{\text {nd }}, 3^{\text {rd }}$ & $\mathrm{n}$ & $1^{\text {st }}, 2^{\text {nd }}, 3^{\text {rd }}$ & $\mathrm{n}$ & $1^{\text {st }}, 2^{\text {nd }}, 3^{\text {rd }}$ & $\mathrm{n}$ \\
\hline All Respondents & $\begin{array}{l}\text { Economic } \\
\text { Environmental } \\
\text { Social }\end{array}$ & 120 & $\begin{array}{l}\text { Economic } \\
\text { Environmental } \\
\text { Social }\end{array}$ & 110 & $\begin{array}{l}\text { Economic } \\
\text { Environmental } \\
\text { Social }\end{array}$ & 104 \\
\hline Producers & $\begin{array}{l}\text { Economic } \\
\text { Environmental } \\
\text { Social }\end{array}$ & 36 & $\begin{array}{l}\text { Economic } \\
\text { Environmental } \\
\text { Social }\end{array}$ & 33 & $\begin{array}{l}\text { Economic } \\
\text { Environmental } \\
\text { Social }\end{array}$ & 30 \\
\hline Research/ Extension & $\begin{array}{l}\text { Economic } \\
\text { Environmental } \\
\text { Social }\end{array}$ & 42 & $\begin{array}{l}\text { Economic } \\
\text { Environmental } \\
\text { Social }\end{array}$ & 48 & $\begin{array}{l}\text { Economic } \\
\text { Environmental } \\
\text { Social }\end{array}$ & 41 \\
\hline Regulators & $\begin{array}{l}\text { Economic } \\
\text { Environmental } \\
\text { Social }\end{array}$ & 25 & $\begin{array}{l}\text { Economic } \\
\text { Environmental } \\
\text { Social }\end{array}$ & 18 & $\begin{array}{l}\text { Economic } \\
\text { Environmental } \\
\text { Social }\end{array}$ & 20 \\
\hline NGO & $\begin{array}{l}\text { Environmental } \\
\text { Economic } \\
\text { Social }\end{array}$ & 17 & $\begin{array}{l}\text { Environmental } \\
\text { Economic } \\
\text { Social }\end{array}$ & 11 & $\begin{array}{l}\text { Environmental } \\
\text { Economic } \\
\text { Social }\end{array}$ & 13 \\
\hline
\end{tabular}


ries, respectively. Separate analyses for each stakeholder group and survey round are not presented but would have required calculating and parsing 69,550 absolute values into 30 different matrices. The R3 all-respondent calculations were considered the relevant information needed for determining the value of each indicator to sustainability measures. Results of the analysis are provided in tables 11-13, where the distance metric (DM) rank also is compared with the mean rank (MR) calculated from the cardinal weights of individual indicators. The DM and MR approach produced consistent results for the highest ranked indicator in each sustainability category, namely water quality, profits and jobs. Comparisons further down in the ranking suggest that MR may not always be useful for determining the relevant order of indicators. For example, indicators E1 and E8 (land use and total ammonia nitrogen discharge) are both ranked 4th according to the consensus ranks generated by the distance metric approach. The MR approach, however, clearly ranked these indicators as distinct from each other, implying a level of consensus that did not exist among the respondents. Similar ties in ranks emerge in tables 12 and 13 for economic and sociological indicators, respectively. In each category, DM and MR ranks differ only slightly. 
Table 11. Comparative ranking of a distance metric (DM) and mean rank (MR) order for environmental indicators of aquaculture sustainability (round 3, $n=104$ ).

\begin{tabular}{llllllllllllll}
\hline & $1^{\text {st }}$ & $2^{\text {nd }}$ & $3^{\text {rd }}$ & $4^{\text {th }}$ & $5^{\text {th }}$ & $6^{\text {th }}$ & $7^{\text {th }}$ & $8^{\text {th }}$ & $9^{\text {th }}$ & $10^{\text {th }}$ & $11^{\text {th }}$ & $12^{\text {th }}$ \\
\hline DM & $E_{5}$ & $E_{2}$ & & $E_{1}$ & & $E_{12}$ & & $E_{4}$ & $E_{3}$ & $E_{7}$ & & $E_{9}$ \\
& & & & $E_{8}$ & & $E_{10}$ & & $E_{11}$ & & & & \\
$M R$ & $E_{5}$ & $E_{6}$ & $E_{2}$ & $E_{8}$ & $E_{1}$ & $E_{10}$ & $E_{12}$ & $E_{4}$ & $E_{11}$ & $E_{3}$ & $E_{7}$ & $E_{9}$ \\
\hline
\end{tabular}

Table 12. Comparative ranking of a distance metric (DM) and mean rank (MR) order for economic indicators of aquaculture sustainability (round 3, $n=104$ ).

\begin{tabular}{lllllllllll}
\hline & $1^{\text {st }}$ & $2^{\text {nd }}$ & $3^{\text {rd }}$ & $4^{\text {th }}$ & $5^{\text {th }}$ & $6^{\text {th }}$ & $7^{\text {th }}$ & $8^{\text {th }}$ & $9^{\text {th }}$ & $10^{\text {th }}$ \\
\hline DM & $\$_{4}$ & $\$_{2}$ & $\$_{9}$ & $\$_{5}$ & & $\$_{1}$ & $\$_{3}$ & & & $\$_{10}$ \\
& & & & $\$_{7}$ & & & $\$_{6}$ & & & \\
MR & $\$_{4}$ & $\$_{2}$ & $\$_{9}$ & $\$_{5}$ & $\$_{7}$ & $\$_{1}$ & $\$_{6}$ & $\$_{3}$ & $\$_{8}$ & $\$_{10}$ \\
\hline
\end{tabular}

Table 13. Comparative ranking of a distance metric (DM) and mean rank (MR) order for sociological indicators of aquaculture sustainability (round 3, $n=104$ ).

\begin{tabular}{llllllllll}
\hline & & \multicolumn{7}{c}{ Rank } \\
& $1^{\text {st }}$ & $2^{\text {nd }}$ & $3^{\text {rd }}$ & $4^{\text {th }}$ & $5^{\text {th }}$ & $6^{\text {th }}$ & $7^{\text {th }}$ & $8^{\text {th }}$ & $9^{\text {th }}$ \\
\hline DM & $\mathrm{S}_{7}$ & $\mathrm{~S}_{6}$ & & $\mathrm{~S}_{5}$ & $\mathrm{~S}_{2}$ & $\mathrm{~S}_{4}$ & $\mathrm{~S}_{1}$ & $\mathrm{~S}_{8}$ \\
& & $\mathrm{~S}_{9}$ & & & & & $\mathrm{~S}_{3}$ & & \\
MR & $\mathrm{S}_{7}$ & $\mathrm{~S}_{6}$ & $\mathrm{~S}_{9}$ & $\mathrm{~S}_{5}$ & $\mathrm{~S}_{2}$ & $\mathrm{~S}_{4}$ & $\mathrm{~S}_{3}$ & $\mathrm{~S}_{1}$ & $\mathrm{~S}_{8}$ \\
\hline
\end{tabular}




\section{Summary and Conclusions}

Many diverse, conflicting groups are actively engaged in an increasingly volatile debate over the proper definition and application of sustainability in aquaculture. Attempts to find common ground on general sustainability goals and parameters have not yet been successful. This study illustrated the potential of using a Delphi approach to identify and refine consensus indicators of sustainability along three separate disciplinary axes: environmental, economic and sociological. The southeastern United States was the geographic context for this study, one of the largest non-military Delphi surveys to have been conducted.

Nonparametric statistical analyses of sustainability categories and indicators indicated a high level of consensus among and between diverse groups. The null hypothesis for Freidman's test, no rank patterns, was rejected $(\alpha=0.05)$ in each of 45 separate tests.

Kendall's coefficient of concordance $(W$ ) was used to measure the degree of agreement each rank case. In general, values for Kendall's $W$ increased across all three survey rounds and reached averages of 0.75-0.8 for sustainability categories and individual groups of indicators. Given the 0 - 1 interval of Kendall's $W$, such relatively large $W$ values constitute high to unusually high levels of agreement and high confidence in the expressed rank orders. The results for the NGO group were a notable exception to these findings. One possible reason this group failed to achieve the same degree of in-group consensus may be their high level of institutional diversity in the southeastern United States. Aquaculture producers, researchers and regulatory agents have a long-standing history and familiarity with the regional aquaculture industry; however, NGOs recruited for this study were relatively difficult to find, because they have not been active in this region. Furthermore, producers and researchers and extension agents exhibited somewhat lower levels of agreement on their expressed rankings for environmental indicators of aquaculture sustainability. This finding is not surprising in that they, especially aquaculture producers, may have been reluctant to suggest environmental indicators with implications for future policy arrangements. 
Economic sustainability is often promoted as the most important category under the general umbrella of aquaculture sustainability. An argument frequently heard is that, without economic viability, environmental and social concerns are effectively moot. Instances of environmental degradation and social unrest in developing countries are frequently cited to support this assertion. Results of distance metric calculations tend to support these claims. Despite some minor initial differences, by R3 the consensus rankings for sustainability categories ordered economic sustainability as the most important for all groups. Further application of the distance metric approach provided specific information on the consensus rank order of aquaculture sustainability indicators. In some cases, however, the distance metric identified subsets of indicators with the same ordinal rank. One implication of this result is the need to reconsider the cardinal weights of tied indicators if such information is ultimately to be used for developing overall indices of aquaculture sustainability. One logical method for re-weighting these indicators would be to assign the mean of tied weights.

The analysis in this study demonstrates that opposing aquaculture groups in the southeastern United States can both identify and refine common goals and measurable indicators of sustainability. More than a successful demonstration of methodology, the resulting indicators represent the raw materials required to construct a quantifiable index of aquaculture sustainability; however, consensus-based indicators alone are operationally insufficient for evaluating aquaculture sustainability. Further work is needed to identify and refine a practical method for their structural and mathematical integration. Such a consensus-based index would be useful in evaluating the environmental, economic and sociological trade-offs of productionlevel aquaculture scenarios in the southeastern United States. 


\section{References}

Asian Institute of Technology Aquaculture (1994) "Partners in Development:

The Promotion of Sustainable Aquaculture," AIT Aquaculture,

Asian Institute of Technology, Bangkok, Thailand, January 1994, p.98.

Bailey, C., S. Jentoft, and P. Sinclair (1996) Aquaculture Development: Social Dimensions of an Emerging Industry (editors), Westview Press, $282 \mathrm{pp}$.

Bardach, J. (1995) Editor: Sustainable Aquaculture '95: Proceedings of the

Pacific Congress on Marine Science and Technology, Honolulu, Hawaii, June 1995, 441 pp.

Browdy, C.L. and J.S. Hopkins (1995) Editors: Swimming Through Troubled Waters: Proceedings of the Special Session on Shrimp Farming, World Aquaculture '97, Seattle, Washington. February 1997.

Brown, L.R., H. Kane, and D.M. Roodman (1994) "Vital Signs: The Trends that are Shaping our Future," World Watch Institute, W.W. Norton and Company, New York, p. 34.

Caffey, R.H. (1998) Quantifying Sustainability in Aquaculture Production, Ph.D. Dissertation, School of Forestry, Wildlife, and Fisheries, Louisiana State University.

Conover, W.J. (1971) Practical Nonparametric Statistics. John Wiley \& Sons Inc. New York.

Cook W.D., and L.M. Seiford (1978) Priority Ranking and Consensus Formation. Management Science, Vol. 24, No. 16, December 1978.

D'Abramo, L.D. and J.H. Hargreaves (1997) Shrimp Aquaculture at the Crossroads: Pathways to Sustainability, World Aquaculture Magazine, Vol. 28 (3), p. 27-48, September 1997.

Edwards, C.A., L. Rattan, P. Madden, R.H. Miller, and G. House (1990) Sustainable Agricultural Systems, St. Lucia Press, Delray Beach, Florida. 696 pp.

Hammond, A., A. Adriaanse, E. Rodenburg., D. Bryant, and R. Woodward (1995) "Environmental Indicators: A systematic Approach to Measuring and Reporting on Environmental Policy Performance in the Context of Sustainable Development," World Resources Institute, May 1995, 53 pp.

Hargreaves, J.A. (1997) The Quest for Sustainable Shrimp Aquaculture: A Moderator's Perspective. World Aquaculture Magazine, Vol. 28 (3), September 1997, pp. 43-48.

Hopkins, S. (1996) " Aquaculture Sustainability: Avoiding the Pitfalls of the Green Revolution,"World Aquaculture Magazine, June 1996, 27 (2). 
Kazmierczak, Jr., R.F., and D.W. Hughes. (1997) "Reasonable Value and the Role of Negotiation in Agriculture's Use of the Environment," Review of Agricultural Economics 19:108-121.

Landesman L. (1994) "Negative impacts of Coastal Aquaculture Development," World Aquaculture, June 1994, Vol. 25 (2), p. 12-17. NADP (1996) Joint Sub-committee on Aquaculture CCREES-PAPPP, Ag. Box, 2204, Washington D.C. 20250-2204

New, M. (1996) Sustainable Global Aquaculture, World Aquaculture Magazine, Vol. 27(2), June 1996, p. 4-6.

Nijkamp, P., P. Rietveld, and H. Voogd (1990) Multicriteria Evaluation in Physical Planning, Elsevier Science Publishers, Amsterdam, The Netherlands, 219 pp.

Pullin, R.S.V., H. Rosenthal, and J.L. Maclean (1993) "Environment and Aquaculture in Developing Countries." ICLARM Conf. Proc., 31, $359 \mathrm{p}$.

Rosenthal, H. (1994) Aquaculture and the Environment, World Aquaculture, June 1994, Vol.25(2), p. 4-11.

Sackman, H. (1975) "Delphi Critique: Expert Opinion, Forecasting, and Group Process," The Rand Corporation, Lexington Books, D.C. Heath and Company, Lexington, Massachusetts.

Sandifer, Paul A. (1995) "Recommendations for Policy Formulation to Enhance Development of Sustainable Coastal Aquaculture," Book of Abstracts, Aquaculture '95. World Aquaculture Society, January 31st, 1995, San Diego, California. p. 205

Schmidt, R.C. (1997) Managing Delphi Surveys Using Nonparametric Statistical Techniques. Decision Sciences, Vol. 28, No.3, Summer 1997.

Serageldin, I. and A. Steer (1994) "Making Development Sustainable: From Concepts to Action," Environmentally Sustainable Development Occasional Paper Series, No. 2. The World Bank, Washington D.C.

Tidwell, J.H. (1995) Editor: Book of Abstracts, World Aquaculture '95:

Quality Products - Quality Environments, San Diego, California, February 1995.

Walter, G. and A. Reisner (1994) "Midwestern Land-Grant University

Scientists' Definition of Sustainable Agriculture: A Delphi Study,"

American Journal of Alternative Agriculture, Vol. 9, No.3.

Vincke, P. (1992) Multicriteria: Decision Aid, John Wiley \& Sons, Ltd. New York, $154 \mathrm{pp}$.

Zar, J.H. (1974) Biostatistical Analysis. Prentice-Hall, Inc., Englewood Cliffs, NJ.

Zuboy, J.R. (1981) “A New Tool for Fisheries Managers: The Delphi Technique," North American Journal of Fisheries Management, 1:55-59. 


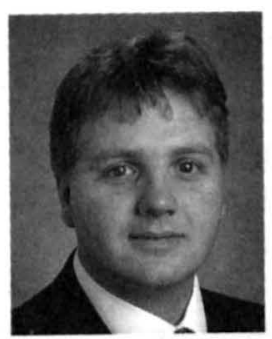

Rex H. Caffey, Ph.D.

Assistant Specialist

Department of Agricultural Economics and Agribusiness

Louisiana Agricultural Experiment Station

Louisiana State University Agricultural Center

Baton Rouge, LA 70803

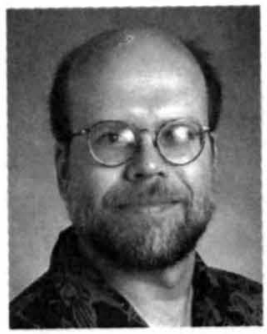

Richard F. Kazmierczak, Jr., Ph.D.

Associate Professor

Department of Agricultural Economics and Agribusiness

Louisiana Agricultural Experiment Station

Louisiana State University Agricultural Center

Baton Rouge, LA 70803

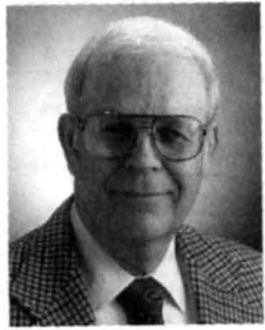

James W. Avault, Jr., Ph.D.

Professor, retired

Department of Forestry, Wildlife, and Fisheries

Louisiana Agricultural Experiment Station

Louisiana State University Agricultural Center

Baton Rouge, LA 70803

Louisiana Agricultural Experiment Station

LSU Agricultural Center

P.O. Box 25055

Baton Rouge, LA 70894-5055

Non-profit Org.

U.S. Postage

PAID

Permit No. 733

Baton Rouge, LA

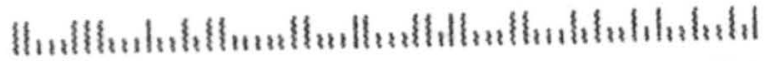

54 P3 **********AUTD**3-DIEIT 708

LSU LIBRARIES SERIALS 